\title{
Thin supported MOF based mixed matrix membranes of Pebax 1657 for biogas upgrade $t$
}

Received 00th January 20xx Accepted 00th January 20xx

DOI: $10.1039 / \times 0 \times x 00000 x$

www.rsc.org/

\author{
Javier Sánchez-Laínez, Inés Gracia-Guillén, Beatriz Zornoza, Carlos Téllez and Joaquín Coronas*
}

\begin{abstract}
This work shows the preparation of thin mixed matrix membranes (MMMs) with 2-3 $\mu$ m thickness of Pebax 1657 on two different supports: porous asymmetric polyimide P84 and dense polytrimethylsilylpropyne (PTMSP). Nanoparticles of metal-organic frameworks (MOFs) ZIF-8, MIL-101(Cr), UiO-66 and ZIF-7/8 core-shells were selected as fillers for the Pebax ${ }^{\circ}$ 1657 based MMMs, all of them being MOFs with high $\mathrm{CO}_{2}$ adsorption capacity but different pore size distribution. All the membranes were characterized by SEM, FTIR, Raman, TGA and XRD, showing in all cases a perfect compatibility of the Pebax ${ }^{*}$ layer with both supports and also a good dispersion of the fillers in the polymeric matrix. These membranes were applied for the separation of equimolar $\mathrm{CO}_{2} / \mathrm{CH}_{4}$ mixtures at $35^{\circ} \mathrm{C}$ under feed pressures between 3 and 5 bar, where an improvement in the gas separation performance with increasing pressure was noticed thanks to the favored solubility of $\mathrm{CO}_{2}$. The synergistic compatibility between Pebax 1657 and $\mathrm{P} 84^{\circ}$ gave rise to a $470 \%$ enhancement in the $\mathrm{CO}_{2} / \mathrm{CH}_{4}$ selectivity, reaching a maximum value of 114 while the $\mathrm{CO}_{2}$ permeance increased by $40 \%$ up to $7.5 \mathrm{GPU}$. The addition of fillers in the Pebax polymeric phase produced an improvement in the gas separation performance of the membranes, especially in terms of permeance, where the MMMs containing 10 wt\% loading of UiO-66 reached the optimum value of $11.5 \mathrm{GPU}^{\mathrm{C}} \mathrm{CO}_{2}$ (together with a $\mathrm{CO}_{2} / \mathrm{CH}_{4}$ selectivity of 55.6).
\end{abstract}

\section{INTRODUCTION}

The biogas production from renewable sources (e.g., from agriculture, landfills, or sewage plants) is one of the fields where membrane technology can develop its greatest potential. ${ }^{1,2}$ The main components of biogas are methane $\left(\mathrm{CH}_{4}\right.$, the combustible component) and carbon dioxide $\left(\mathrm{CO}_{2}\right.$, the non-combustible component), although it also typically contains traces of $\mathrm{H}_{2} \mathrm{O}$, $\mathrm{N}_{2}, \mathrm{H}_{2} \mathrm{~S}$ and other organic aromatics. ${ }^{3}$ The high concentration of $\mathrm{CO}_{2}$ and $\mathrm{CH}_{4}$ in the mixture, basically in the same proportion, makes the biogas upgrading appropriate to be carried out with polymeric membranes, a technology that offers advantages such as low energy costs and environmental benignity, ${ }^{4}$ and that can be an alternative to other existing approaches, such as cryogenic upgrading or liquefaction. ${ }^{5}$ For example, PVAm/PVA blends have shown a $\mathrm{CH}_{4}$ recovery of $99 \%$ at low running cost in a 2-stage recycled process. ${ }^{6}$ Besides purifying the $\mathrm{CH}_{4}$ flow, the captured $\mathrm{CO}_{2}$ is also suitable for its conversion to high added value products, such as $\mathrm{MeOH} .^{7}$

The major materials for membranes are polyimides and fluoropolymers. ${ }^{8}$ To obtain membranes with a good gas separation performance (i.e. high $\mathrm{CO}_{2}$ permeation flux and

Chemical and Environmental Engineering Department, Instituto de Nanociencia de Aragón (INA), Universidad de Zaragoza, 50018 Zaragoza, Spain. Email: coronas@unizar.es

+ Electronic Supplementary Information (ESI) available: MOF synthesis, membrane characterization and gas separation performance. See DOI: 10.1039/x0xx00000x
$\mathrm{CO}_{2} / \mathrm{CH}_{4}$ selectivity), materials with intrinsic separation capacity for the target mixture are necessary. Poly(ether-block-amide), best known under the trademark Pebax ${ }^{\circ}$, constitutes a family of polymers that possesses these advantageous properties. These polymers combine linear chains of rigid polyamide with flexible, $\mathrm{CO}_{2}$-philic polyether segments, building crystalline/amorphous structures that show the properties of both thermoplastics and rubbers. It is believed that the hard amide block provides the mechanical strength, whereas gas selective transport occurs primarily through the soft ether block. ${ }^{9}$ The polyamide/polyetheroxide proportion in the blend determines the Pebax ${ }^{\circ}$ grade. The membranes in this work were prepared with Pebax 1657 , consisting of $40 \mathrm{wt} \%$ of polyamide. ${ }^{10}$

Membranes with high permeance are essential for large-scale applications, such as biogas upgrading. ${ }^{11}$ This variable is not only related to the membrane permeability but also to the thickness of the membrane, and membranes consisting of a very thin selective layer are necessary to achieve this goal. Such highly performing membranes can be prepared as composite materials, where the selective layer is deposited on a highly porous support that provides mechanical stability. ${ }^{12}$ Pebax ${ }^{\circ}$ 1657 can be found in the literature in the form of thin film composites on several polymeric supports, such as polyvinylidene fluoride (PVDF), ${ }^{13,14}$ polyacrylonitrile (PAN) ${ }^{15,16}$ and polysulfone. ${ }^{17,18}$ The $\mathrm{CO}_{2}$ permeances vary from 13 to 670 GPU according to the membrane morphology and the $\mathrm{CO}_{2} / \mathrm{CH}_{4}$ selectivities are comprehended between 13.6 and 18.0. These 


\section{NJC}

\section{PAPER}

works also provide $\mathrm{CO}_{2} / \mathrm{N}_{2}$ selectivities, which show highly dispersed values (between 32 and 70).

In general, the gas separation performance of polymeric membranes can be enhanced through the concept of mixed matrix membranes (MMMs), consisting of the dispersion of inorganic fillers within a polymeric matrix so that either or both the permeability and selectivity of the membrane can be improved through the synergistic combination of the two components. ${ }^{19}$ Metal-organic frameworks (MOFs) are materials that have been widely used as fillers in MMMs. In the case of the Pebax 1657 polymer, ZIF-8 has been used as filler by Xu et. al. ${ }^{20}$ and Zehng et. al. ${ }^{21}$ The former found an increase in the $\mathrm{CO}_{2}$ permeability from 79.2 to 156 Barrer as the ZIF-8 loading increased from 0 to $20 \mathrm{wt} \%$, but the $\mathrm{CO}_{2} / \mathrm{N}_{2}$ selectivity decreased until 40.5. The latter showed fluctuating $\mathrm{CO}_{2}$ permeabilities between 55.8 and 179 Barrer and practically constant $\mathrm{CO}_{2} / \mathrm{N}_{2}$ and $\mathrm{CO}_{2} / \mathrm{CH}_{4}$ selectivities. Within the ZIFs family, ZIF-7 has also been used as filler in Pebax 1657 membranes. Li et. al. ${ }^{22}$ prepared thin Pebax 1657 based MMMs supported on PAN that showed the best performance results at 34 wt\% loading with a $\mathrm{CO}_{2}$ permeance of $39 \mathrm{GPU}$, and $\mathrm{CO}_{2} / \mathrm{N}_{2}$ and $\mathrm{CO}_{2} / \mathrm{CH}_{4}$ selectivities of 105 and 44 , respectively. ZIF-7 has also been used as filler by Sutrisna et. al. ${ }^{13}$ who prepared MMMs on PVDF hollow fibers with optimum values of $300 \mathrm{GPU}$ of $\mathrm{CO}_{2}$, with $\mathrm{CO}_{2} / \mathrm{N}_{2}$ and $\mathrm{CO}_{2} / \mathrm{CH}_{4}$ selectivities of 47.5 and 17.0, respectively. Other MOF-Pebax 1657 combinations for dense MMMs included MOFs ZIF-94, $\mathrm{NH}_{2}-\mathrm{MIL}-53(\mathrm{Al}), \mathrm{MIL}-69$ (AI) and MIL-96(Al), with the latter giving rise to best $\mathrm{CO}_{2} / \mathrm{N}_{2}$ performance: permeability and selectivity enhanced by 25 and $18 \%$, respectively, as compared to the pure polymer. ${ }^{23}$ Interestingly, the effect of the MOF functionalization (comparing the use of MIL-53(Al) and $\mathrm{NH}_{2}-\mathrm{MIL}-53(\mathrm{Al})$ with better $\mathrm{CO}_{2}$ permeability and $\mathrm{CO}_{2} / \mathrm{CH}_{4}$ selectivity values for the latter) has been recently studied on dense MMMs with Pebax ${ }^{\circ}$ $1657 .{ }^{24}$ There is no doubt that 1657 is the most Pebax code used in the MMM field.

This work shows the preparation of thin film composite membranes with a thin mixed-matrix selective top layer MOF/polymer Pebax 1657 for biogas upgrade. The membranes have been prepared on different polymeric supports and the influence of the feed pressure on the gas separation performance has been studied. Different MOFs (ZIF-8, ZIF-7/8 core-shells, UiO-66 and MIL-101(Cr)) have been embedded in Pebax ${ }^{\circledR} 1657$, dissolved in a water-ethanol mixture, ${ }^{25}$ as fillers to obtain thin supported MMMs. Materials with a high $\mathrm{CO}_{2}$ uptake (see Table 1) have been selected to favor the solubility of this gas in the membrane composite and thus enhance its $\mathrm{CO}_{2} / \mathrm{CH}_{4}$ separation performance.

\begin{tabular}{|c|c|c|c|c|c|}
\hline MOF & Adsorption conditions & $\begin{array}{c}\mathrm{CO}_{2} \text { uptake, } \\
\left(\mathrm{mmol} \mathrm{g}^{-1}\right)\end{array}$ & $\begin{array}{c}\text { Pore aperture } \\
\text { (nm) }\end{array}$ & $\begin{array}{l}\text { Cavity } \\
\text { (nm) }\end{array}$ & Ref. \\
\hline \multirow[t]{2}{*}{ ZIF-8 } & $273 \mathrm{~K}, 1$ bar & 1.3 & \multirow[t]{2}{*}{0.34} & \multirow[t]{2}{*}{1.16} & \multirow[t]{2}{*}{26,27} \\
\hline & $298 \mathrm{~K}, 30$ bar & 35 & & & \\
\hline \multirow[t]{2}{*}{ UiO-66 } & $273 \mathrm{~K}, 1$ bar & 2.4 & \multirow[t]{2}{*}{0.80} & \multirow[t]{2}{*}{2.1} & \multirow[t]{2}{*}{$28-30$} \\
\hline & $300 \mathrm{~K}, 35$ bar & 7.0 & & & \\
\hline \multirow[t]{2}{*}{ MIL-101(Cr) } & $303 \mathrm{~K}, 1$ bar & 1.6 & \multirow[t]{2}{*}{$1.2-1.6$} & \multirow[t]{2}{*}{$2.9-3.4$} & \multirow[t]{2}{*}{$31-33$} \\
\hline & $304 \mathrm{~K}, 50$ bar & 40 & & & \\
\hline ZIF-7/8 core-shells & $273 \mathrm{~K}, 1$ bar & 2.5 & $0.29-0.34$ & $0.43-1.16$ & 26 \\
\hline
\end{tabular}




\section{NJC}

\section{EXPERIMENTAL SECTION}

\subsection{Synthesis of MOF nanoparticles}

Four different MOFs were synthesized to be used as fillers in the MMMs of this work. The ZIF-8 synthesis was performed following a recipe based on a $\mathrm{MeOH}$-water mixture as solvent. ${ }^{34}$ UiO-66 was synthesized solvothermally in $\mathrm{N}, \mathrm{N}$ dimethylformamide (DMF, 99.8\%, Sigma-Aldrich). ${ }^{35}$ The synthesis of MIL-101(Cr) was microwave assisted, using DI water as solvent for the metal source and the ligand. ${ }^{36}$ And finally, the ZIF-7/8 core-shells were prepared via post-synthetic modification of the firstly explained ZIF- 8 nanoparticles. ${ }^{26}$ The experimental details are described in the Supporting Information.

\subsection{Membrane preparation}

P84 ${ }^{\circledR}$ asymmetric supports. Flat asymmetric porous $\mathrm{P} 84^{\circ}$ supports were prepared following the phase inversion method. ${ }^{37}$ A 23 wt\% dope solution of $\mathrm{P} 84^{\circ}$ (HP polymer $\mathrm{GmbH}$ ) was prepared dissolving the corresponding amount of powder in N,N-dimethylacetamide (DMAc, >99,8\% Sigma Aldrich). The polymer solution was cast on a glass plate using the Elcometer 4340 Automatic Film Applicator placed in a fume hood and set at a thickness of $250 \mu \mathrm{m}$. Immediately afterwards the resultant polymer sheets were immersed into a tap water bath at $25{ }^{\circ} \mathrm{C}$ for $10 \mathrm{~min}$. After precipitation, the membranes were kept in a deionized (DI) water bath overnight and then rinsed with IPA to remove the remaining DMAc. The films were dried at $100{ }^{\circ} \mathrm{C}$ for one day prior to use.

Before testing the gas separation performance, several membranes were treated with PDMS (Sylgard ${ }^{\circledR}$ 184, Dow Corning) by dip coating. The coating solution was prepared mixing PDMS polymer base and the hardener (dimethyl, methylhydrogen siloxane) provided with the Sylgard ${ }^{\circledR}$ kit with a weight ratio of 10 to 1 . The mixture was added to $n$-hexane to obtain a 3 wt\% solution. The membranes were immersed in the coating solution for $5 \mathrm{~min}$, and then allowed to evaporate at room temperature for $2 \mathrm{~h}$. Finally, the membranes were cured in an oven at $100{ }^{\circ} \mathrm{C}$ for $18 \mathrm{~h}$.

Dense PTMSP supports. For the preparation of PTMSP dense supports, the polymer was first dissolved at room temperature in hexane at $5 \mathrm{wt} \%$ concentration. The solution was then cast on a glass Petri dish and allowed to dry at room temperature for $24 \mathrm{~h}$. The obtained film was immersed in $\mathrm{MeOH}$ for another $24 \mathrm{~h}$ to remove traces of solvent and dried afterwards at $100^{\circ} \mathrm{C}$ for $24 \mathrm{~h}$ more. The resulting films had a thickness of around 80 $\mu \mathrm{m}$.
Pebax $^{\circledR} 1657$ membranes. Thin films of Pebax 1657 were prepared on the two previously described supports (asymmetric porous $\mathrm{P} 84^{\circ}$ and dense PTMSP) following a solution-casting procedure. Pellets of Pebax ${ }^{\circledR}$ (kindly provided by Arkema) were dissolved in a $70 / 30(\mathrm{v} / \mathrm{v}) \mathrm{EtOH} / \mathrm{H}_{2} \mathrm{O}$ mixture by refluxing at $90^{\circ} \mathrm{C}$ for $1 \mathrm{~h}$. The polymer solution was then cast on the corresponding support using the same film applicator as before. Afterwards, the membrane was kept at room temperature for 1 day for complete solvent evaporation. In the case of the Pebax MMMs, the corresponding amount of MOF (ZIF-8, UiO-66, MIL-101(Cr) or ZIF-7/8 core-shells) was dispersed in the EtOH/ $\mathrm{H}_{2} \mathrm{O}$ mixture. Afterwards, the pellets of Pebax ${ }^{\circ}$ were added and the suspension was heated at $90{ }^{\circ} \mathrm{C}$ until the full dissolution of the polymer after ca. $1 \mathrm{~h}$. Then the suspension was cast on the polymeric supports and allowed to dry, as explained above. The casting solution had to be used within few hours because long storage times led to defective films. Self-supported membranes of the bare polymer Pebax ${ }^{\circ}$, with an approximate thickness of $80 \mu \mathrm{m}$, were also prepared for comparison issues. In this case the polymer solution was poured into a Petri dish and the solvent was allowed to evaporate slowly for $72 \mathrm{~h}$ at room temperature.

\subsection{Membrane characterization}

Thermogravimetric analyses (TGA) were carried out using a Mettler Toledo TGA/STDA 851e. Samples $(10 \mathrm{mg})$ placed in 70 $\mu \mathrm{L}$ alumina pans were heated in $40 \mathrm{~cm}^{3}$ (STP) $\mathrm{min}^{-1}$ of air flow from 25 to $900{ }^{\circ} \mathrm{C}$ at a heating rate of $10{ }^{\circ} \mathrm{C} \mathrm{min}{ }^{-1}$. Differential scanning calorimetry (DSC) analyses were performed on a Mettler Toledo DSC822e. Samples (10 mg) placed in $70 \mu \mathrm{L}$ aluminum pans were heated in $40 \mathrm{~cm}^{3}$ (STP) $\mathrm{min}^{-1}$ of nitrogen flow from 25 to $500{ }^{\circ} \mathrm{C}$ at a heating rate of $10^{\circ} \mathrm{C} \mathrm{min}^{-1}$. Scanning electron microscopy (SEM) images of the MOFs and membranes were obtained using a FEI Inspect F50 model SEM, operated at $20 \mathrm{kV}$. Cross-sections of the membranes were prepared by freeze-fracturing after immersion in liquid $\mathrm{N}_{2}$ and subsequently coated with Pt. Fourier transform infrared spectroscopy (FTIR) was performed on the MOF powders and on the different membrane samples, using a Bruker Vertex 70 FTIR spectrometer equipped with a DTGS detector and a Golden Gate diamond ATR accessory. The spectra were recorded on the Pebax ${ }^{\oplus}$ side by averaging 40 scans in the 4000 $600 \mathrm{~cm}^{-1}$ wavenumber range at a resolution of $4 \mathrm{~cm}^{-1}$. Membranes were also characterized by Raman spectroscopy using a WiTec Alpha300 Confocal Raman Microscope, with a $785 \mathrm{~nm}$ laser excitation beam. X-ray diffraction (XRD) patterns of the MOFs and MMMs were obtained with Panalytical Empyrean equipment, using $\mathrm{CuK}_{\alpha}$ radiation $(\lambda=1.540 \AA$ ) , taking data from $2 \theta=2.5^{\circ}$ to $40^{\circ}$ at a scan rate of $0.03^{0} \mathrm{~s}^{-1}$. 


\section{NJC}

\section{PAPER}

\section{$2.4 \quad$ Gas separation analysis}

The membrane samples were placed in a module consisting of two stainless steel pieces and a 316LSS macroporous disk support of $3.14 \mathrm{~cm}^{2}$ (from Mott Co.) with a $20 \mu \mathrm{m}$ nominal pore size, and gripped inside with silicon O-rings. The permeation module was placed in a UNE 200 Memmert oven to control the temperature of the experiments. Gas separation measurements were carried out by feeding a $\mathrm{CO}_{2} / \mathrm{CH}_{4}$ equimolar mixture $\left(25 / 25 \mathrm{~cm}^{3}(\mathrm{STP}) \cdot \mathrm{min}^{-1}\right)$ at 3-5 bar to the feed side by means of two mass-flow controllers (Alicat Scientific, MC-100CCM-D), while the permeate side of the membrane was swept with a $1 \mathrm{~cm}^{3}$ (STP) $\mathrm{min}^{-1}$ mass-flow controlled stream of He at 1 bar (Alicat Scientific, MC-5CCM-D). Concentrations of
$\mathrm{CO}_{2}$ and $\mathrm{CH}_{4}$ in the outgoing streams were analyzed by an Agilent 3000A online gas microchromatograph equipped with a thermal conductivity detector. Permeances were calculated in GPU $\left(10^{-6} \mathrm{~cm}^{3}\right.$ (STP) $\left.\mathrm{cm}^{-2} \mathrm{~s}^{-1} \mathrm{~cm} \mathrm{Hg}^{-1}\right)$ once the steady-state of the membrane module exit stream was reached (for at least $3 \mathrm{~h}$ ), and the separation selectivity was calculated as the ratio of permeances. At least 2-3 membrane samples of each type were fabricated and measured to provide the corresponding error estimations.

\section{RESULTS AND DISCUSSION}

\subsection{Membrane characterization}
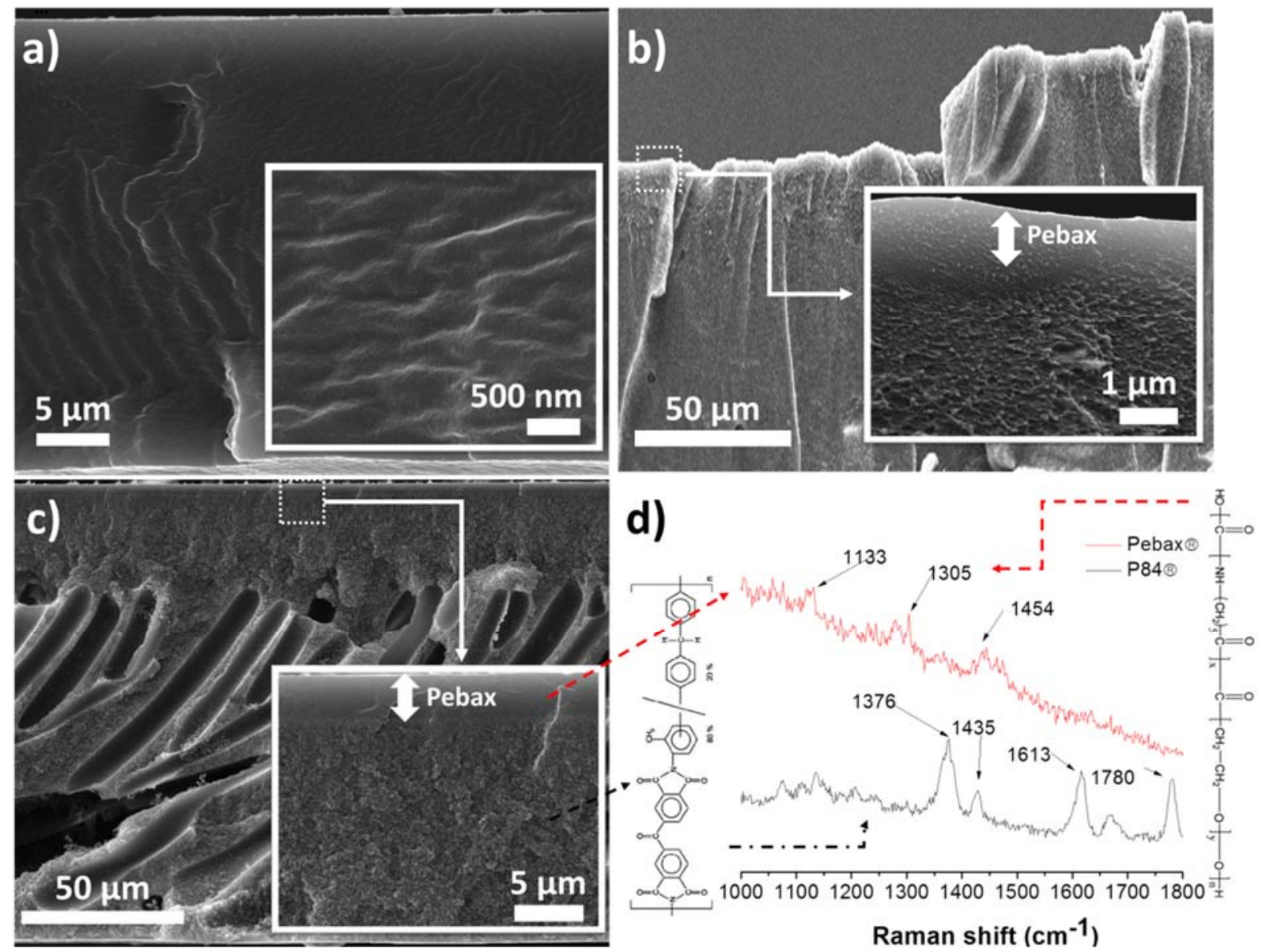

Fig. 1. SEM images with higher magnification insets of the cross-sections of: Pebax ${ }^{\circ} 1657$ self-supported dense membrane (a), Pebax ${ }^{\circ} 1657$ supported on PTMPS (b), and Pebax 1657 supported on asymmetric P84. ${ }^{\circ}$. The Raman spectra corresponding to the latter are also provided (d). 
¡Error! No se encuentra el origen de la referencia. shows the cross-sections of three different membranes based on Pebax ${ }^{\circ}$ 1657: a self-supported dense Pebax 1657 membrane of around $80 \mu \mathrm{m}$ thickness (iError! No se encuentra el origen de la referencia.a) and two supported Pebax 1657 membranes prepared on dense PTMSP and asymmetric P $84^{\circ}$ supports (iError! No se encuentra el origen de la referencia.b and 1c, respectively). The cross-section of the Pebax ${ }^{\infty} 1657 / \mathrm{P}^{\circ} 4^{\circ}$ composite shows a thickness of $120 \mu \mathrm{m}$ for the P84 support, of which $15 \mu \mathrm{m}$ corresponds to the denser top layer. Moreover, it can be observed in the inset at higher magnification that the Pebax 1657 layer is approximately $3 \mu \mathrm{m}$ thick and shows a good adhesion to the polyimide support. A good compatibility can also be observed in the composite membrane prepared on PTMSP, the Pebax 1657 layer being in this case $2 \mu \mathrm{m}$ thick. The cross-sections of the supported (on asymmetric P84 ${ }^{\circ}$ )

Fig. 1d shows the Raman spectra of the cross-section of the

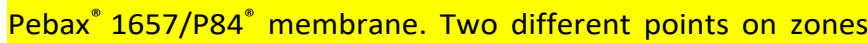
corresponding to the Pebax 1657 layer and the $\mathrm{P} 84^{\circ}$ support were measured. Although the Pebax 1657 Raman spectrum shows weak signals owing to its fluorescence, three peaks can be distinguished at 1133,1305 and $1454 \mathrm{~cm}^{-1}$ related to the $\mathrm{C}$ $\mathrm{O}$ and $\mathrm{C}=\mathrm{O}$ vibration modes. ${ }^{38}$ Signals in the $1300-1800 \mathrm{~cm}^{-1}$ range can be seen in the $P 84^{\circ}$ spectrum. The signals at 1376 and $1435 \mathrm{~cm}^{-1}$ correspond to the $\mathrm{C}=\mathrm{O}$ in-phase stretching mode. The band at $1613 \mathrm{~cm}^{-1}$ is related to the aromatic ring stretching mode, and that at $1780 \mathrm{~cm}^{-1}$ to the aromatic C-N stretching. ${ }^{39}$

Pebax $1657 \mathrm{MMMs}$ are shown in Fig. 2. Membranes containing 10 wt\% loading of ZIF-8, UiO-66, MIL-101(Cr) and ZIF-7/8 coreshell particles can be seen at three different magnifications. By visual inspection a good dispersion of the different fillers in the Pebax ${ }^{\oplus}$ thin layer can be observed, resulting in homogeneous membranes where a good filler-polymer adhesion is noticeable. SEM images of the fillers are also provided (see Fig. S1 from the ESI + ), from which the cumulative and differential particle size distributions were obtained using the Image $1.49 \mathrm{~b}$ software, together with median particle sizes of 150, 25, 33 and $124 \mathrm{~nm}$ for ZIF-8, UiO-66, MIL-101(Cr) and ZIF-7/8 core-shell particles, respectively (see Fig. S2 and Table S1 from the ESI ${ }^{+}$).

Fig. 3 shows the XRD patterns of the different membranes and MOFs and that of the pure polymeric Pebax ${ }^{\circledR} 1657$ membrane for comparison. Pristine Pebax 1657 is a semicrystalline copolymer which consists of both crystalline and amorphous PEO and PA6 phases, showing characteristic peaks at $2 \theta=5.8^{\circ}$, $12.6^{\circ}$ and $24.4^{\circ} .{ }^{40}$ These signals are also noticeable in the patterns of the MMMs, although with lower intensity due to the higher crystallinity of the fillers. It is also clear that ZIF- 8 and UiO-66 maintain their crystallinity in the polymer matrix since

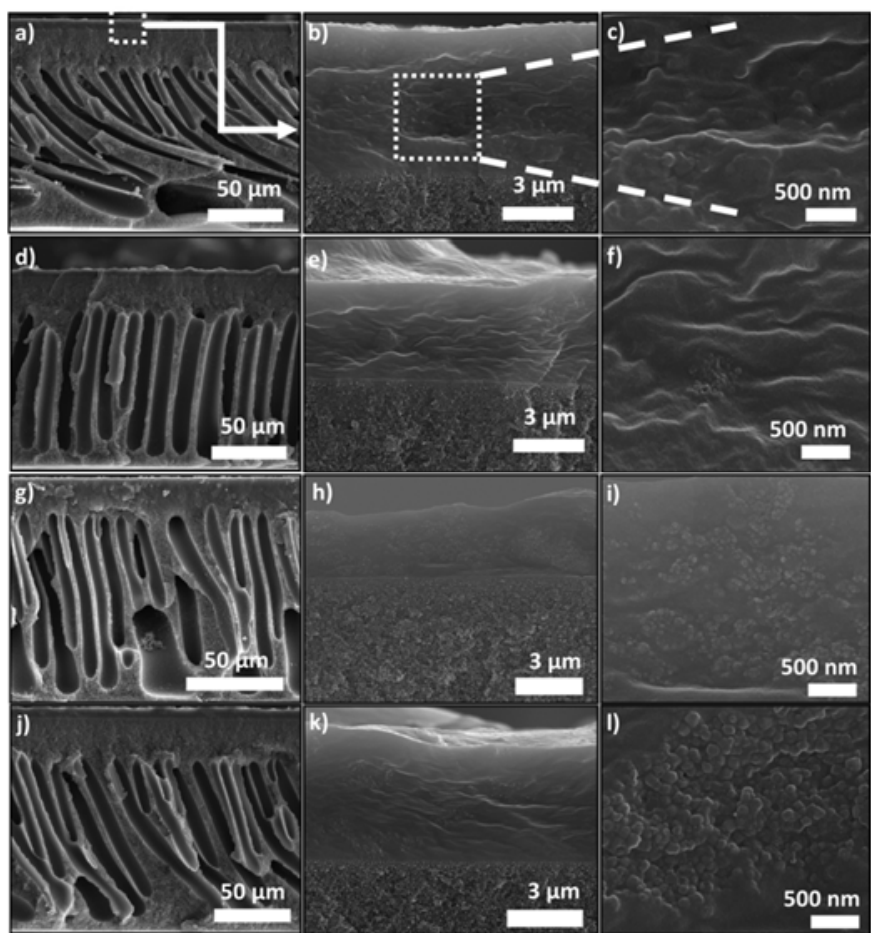

Fig. 3. SEM images of the cross-section of Pebax supported (on asymmetric
P84 $\mathrm{e}, \mathrm{f})$, UiO-66 $(\mathrm{g}, \mathrm{h}, \mathrm{i})$ and ZIF-7/8 core-shell particles $(\mathrm{j}, \mathrm{k}, \mathrm{l})$

their XRD reflections dominate over the polymer amorphous band. In the case of the other two MOFs, the peaks are not so well defined. This is due to the lower crystallinity of MIL-101(Cr) and to the fact that ZIF-7/8 core-shells are not as crystalline as the original ZIF- 8 from which they are synthesized, according to our previous study. ${ }^{26}$ Besides, after the incorporation of the MOFs, the peak positions of Pebax 1657 remained almost unaltered, proving that there were no changes in the $d$ spacings of the polymer.

FTIR spectra were conducted to further characterize and analyze the Pebax 1657 MMMs (see Fig. S3 from the ESI+). The observed peak at $1094 \mathrm{~cm}^{-1}$ is attributed to the stretching vibration of the C-O-C group of the soft segment part of PEO. ${ }^{40}$ Regarding the hard segment of PA chains, the peak corresponding to the $-\mathrm{N}-\mathrm{H}-$ linkages is found at $3298 \mathrm{~cm}^{-1}$ and the characteristic peak at $1636 \mathrm{~cm}^{-1}$ is assigned to the $\mathrm{H}-\mathrm{N}-\mathrm{C}=\mathrm{O}$ group. ${ }^{41}$ The most intense signals of each MOF can be found in the corresponding MMM spectrum. However, none of the membranes show new absorbance peaks, suggesting weak chemical interaction between the filler nanoparticles and the polymer chains or that the filler loading is too low for their visualization. 


\section{NJC}

\section{PAPER}

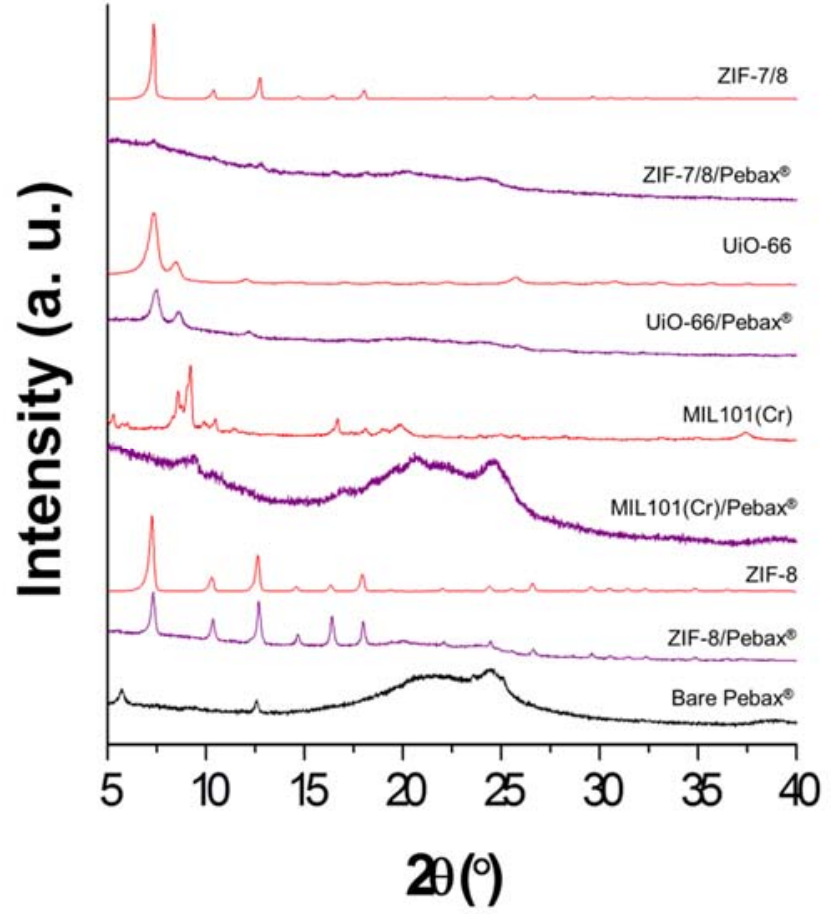

Fig. 4. XRD spectra of bare Pebax 1657 , MMMs and MOF powders.

Thermogravimetric analyses (TGA) in flowing air were used to elucidate the thermal stability of the different membranes prepared in this work. As seen in Fig. S4 from the ESIt, while the P84 support shows an onset temperature of $592{ }^{\circ} \mathrm{C}$, Pebax ${ }^{\circ}$ 1657 was less stable since it started to degrade at around 400 ${ }^{\circ} \mathrm{C}$. This is consistent with a slightly reduced thermal stability for the supported Pebax ${ }^{\circ} 1657 / \mathrm{P}^{\circ} 4^{\circ}$ composite. Regarding the MMMs, the thermograms show that all the MOFs started their decomposition over $300^{\circ} \mathrm{C}$. Besides, these TGA analyses helped to verify that the actual MOF content in the mixed matrix thin layer (12.5 wt\% for ZIF-8, 8.2 wt\% for MIL-101(Cr), $10.9 \mathrm{wt} \%$ for UiO-66 and 13.4 wt\% for ZIF-7/8 MMMs) fit with the nominal (10 wt\%). The thermal properties of Pebax 1657 were further investigated by DSC (see Fig. S5 from the ESI+) Pristine Pebax ${ }^{\circ}$ 1657 shows two endothermic peaks whose maxima occur approximately at 40 and $130{ }^{\circ} \mathrm{C}$. These can be attributed to the fusion of the crystalline fraction of the blocks of poly(ethylene oxide) and polyamide, and limit the operating temperature of the membranes. ${ }^{42}$
The different membranes prepared were tested for the separation of the $\mathrm{CO}_{2} / \mathrm{CH}_{4}$ equimolar mixtures at $35{ }^{\circ} \mathrm{C}$ and under different feed pressures from 3 to 5 bar.

Fig. 4 depicts the gas separation performance of pristine Pebax 1657 membranes. Three different types of membranes were studied, self-supported Pebax 1657 membranes and supported Pebax 1657 using supports of two different polymers: dense PTMSP and asymmetric porous $\mathrm{P} 84^{\circ}$. Thick self-supported Pebax ${ }^{\circledR} 1657$ and thin Pebax 1657 supported on PTMSP showed similar $\mathrm{CO}_{2} / \mathrm{CH}_{4}$ selectivities, with values around 20. However, the difference in $\mathrm{CO}_{2}$ permeance was much more noticeable since the former showed only $1.5 \mathrm{GPU}$ while that of the latter raised up to $64 \mathrm{GPU}$. This is consistent with the difference in thickness between both membranes: 80 $\mu \mathrm{m}$ for the self-supported membrane vs. $2 \mu \mathrm{m}$ of the supported membrane. Taking into account the corresponding value of this parameter for each membrane, the calculated $\mathrm{CO}_{2}$ permeability would be around 120 Barrer in both cases. This highlights the reliability of the membrane permeation characterization system.

When testing the Pebax ${ }^{\circ} 1657$ supported on $\mathrm{P} 84^{\circ}$ also at 3 bar, the $\mathrm{CO}_{2}$ permeance was $6.0 \mathrm{GPU}$, the flow increase being smaller than for the previous PTMSP supported membrane. Nevertheless, the $\mathrm{CO}_{2} / \mathrm{CH}_{4}$ selectivity increased considerably, reaching a value of 79.2 , four-fold higher than that of the selfsupported membrane. This behavior means that the $\mathrm{P} 84^{\circ}$ support is affecting the gas separation performance of the composites, increasing the membrane selectivity and simultaneously decreasing the gas permeability. For a better understanding of the role that the $\mathrm{P} 84^{\circ}$ support was playing in the gas separation, the support itself was tested for the $\mathrm{CO}_{2} / \mathrm{CH}_{4}$ separation (see Table S2 from the ESI + ). The results showed that the $\mathrm{P} 84^{\circ}$ support performed a $\mathrm{CO}_{2}$ permeance of $270 \mathrm{GPU}$ but had no $\mathrm{CO}_{2} / \mathrm{CH}_{4}$ selectivity. When the $\mathrm{P} 84^{\circ}$ was coated with PDMS the permselectivity enhanced by defect healing, but only the inherent $\mathrm{CO}_{2} / \mathrm{CH}_{4}$ selectivity of PDMS was noticeable (5.5), as well as its $\mathrm{CO}_{2}$ permeance (55.1 GPU). ${ }^{43}$ This fact means that $P 84^{\circ}$ and Pebax 1657 possess a specific compatibility, building a composite whose gas separation performance is much better than that of the bare polymers. Besides, coating the polyimide $\mathrm{P} 84^{\circ}$ support with a more selective polymer such as Pebax 1657 may lead to a healing effect and the selectivity of the polyimide would approach values found in the literature for this polymer $\left(\mathrm{CO}_{2} / \mathrm{CH}_{4}\right.$ selectivity of 33.4). ${ }^{44}$

The effect of the feed pressure on the gas separation performance of the $\mathrm{CO}_{2} / \mathrm{CH}_{4}$ mixture was also studied. As seen in Fig. 4, the supported Pebax ${ }^{\circ} 1657 / \mathrm{P}^{\circ} 4^{\circ}$ membranes were 


\section{NJC}

\section{PAPER}

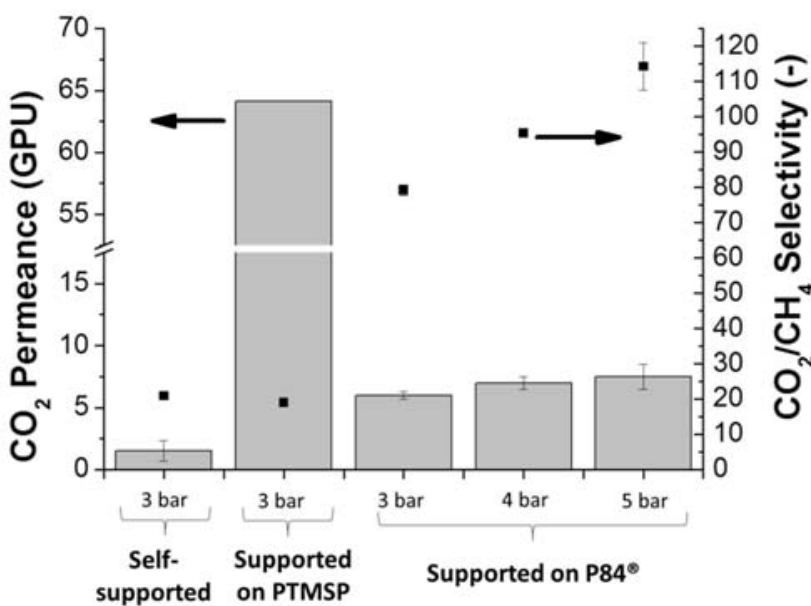

Fig. 6. Gas separation performance of pristine Pebax ${ }^{\star} 1657$ membranes at 35 ${ }^{\circ} \mathrm{C}$ and under different feed pressures: self-supported and supported on selectivity.

tested from 3 to 6 bar, showing that the increase in pressure implied an augment in both the $\mathrm{CO}_{2}$ permeance and the $\mathrm{CO}_{2} / \mathrm{CH}_{4}$ selectivity, reaching the optimum values at 6 bar with $7.5 \mathrm{GPU}$ and 114, respectively. The higher permeance of $\mathrm{CO}_{2}$ results from its smaller molecular diameter in combination with its enhanced solubility due to its high quadrupole moment (4.30 DÅ for $\mathrm{CO}_{2}$ vs. $0.02 \mathrm{DA}$ for $\mathrm{CH}_{4}$ ), which enables strong specific interactions with the polar polyether groups in Pebax ${ }^{\circ}{ }^{10}$ Moreover, the $\mathrm{CH}_{4}$ permeance showed the contrary tendency, decreasing at the higher feed pressures tested. A similar reduction of permeation flux resulting from compression has been reported for $\mathrm{N}_{2}$ and $\mathrm{CH}_{4}$ in rubbery polymers such as PDMS and poly(octylmethylsiloxane) (POMS). ${ }^{45,46}$ Besides, as seen in Fig. S6 from the ESIt, both $\mathrm{CO}_{2}$ and $\mathrm{CH}_{4}$ permeances follow an exponential tendency as a function of feed pressure as described by Stern et al. ${ }^{47}$ (Equation S1), with beta (the constant characteristic of the penetrant-membrane system at the testing temperature, $35^{\circ} \mathrm{C}$ in this case) values positive for $\mathrm{CO}_{2}\left(0.11 \mathrm{bar}^{-1}\right)$ and negative for $\mathrm{CH}_{4}\left(-0.18\right.$ bar $\left.^{-1}\right)$.

Membranes based on Pebax 1657 and using ZIF-8, UiO-66, MIL-101(Cr) and ZIF-7/8 core-shell particles as fillers have been prepared on $\mathrm{P} 84^{\circ}$ supports, obtaining thin supported MMMs. These MOFs have been selected because of their high $\mathrm{CO}_{2}$ uptake (1.3-2.5 mmol. $\mathrm{g}^{-1}$ at $1 \mathrm{bar}$, see Table 1 ) in order to favor the solubility of this gas over $\mathrm{CH}_{4}$ in the Pebax 1657 based MMMs. Only MIL-101(Cr) has cavities in the mesoporous range, while the other MOFs are microporous materials (see Table 1). Fig. 5a shows the gas separation performance of these
MMMs at $35{ }^{\circ} \mathrm{C}$. Two different feed pressures of 3 and 5 bar were tested showing that, as in the previous separation with pristine Pebax 1657 (see Fig. 4), both the $\mathrm{CO}_{2}$ permeance and the $\mathrm{CO}_{2} / \mathrm{CH}_{4}$ selectivity enhanced with increasing pressure. In terms of $\mathrm{CO}_{2}$ permeance, the gas separation performance of the membranes improved with the incorporation of MOFs to the polymeric matrix. MMMs showed an average increase in $\mathrm{CO}_{2}$ permeance of $6 \%$, except for the UiO-66 MMMs, which showed a much greater improvement with a maximum value of 11.5 GPU at 5 bar, almost twice that of pristine Pebax 1657 at the same feed pressure. Regarding the $\mathrm{CO}_{2} / \mathrm{CH}_{4}$ selectivity, its value decreased to one half when any of the fillers were incorporated into Pebax 1657. Nevertheless, $\mathrm{CO}_{2} / \mathrm{CH}_{4}$ selectivities remained high with values between 50 and 60 for
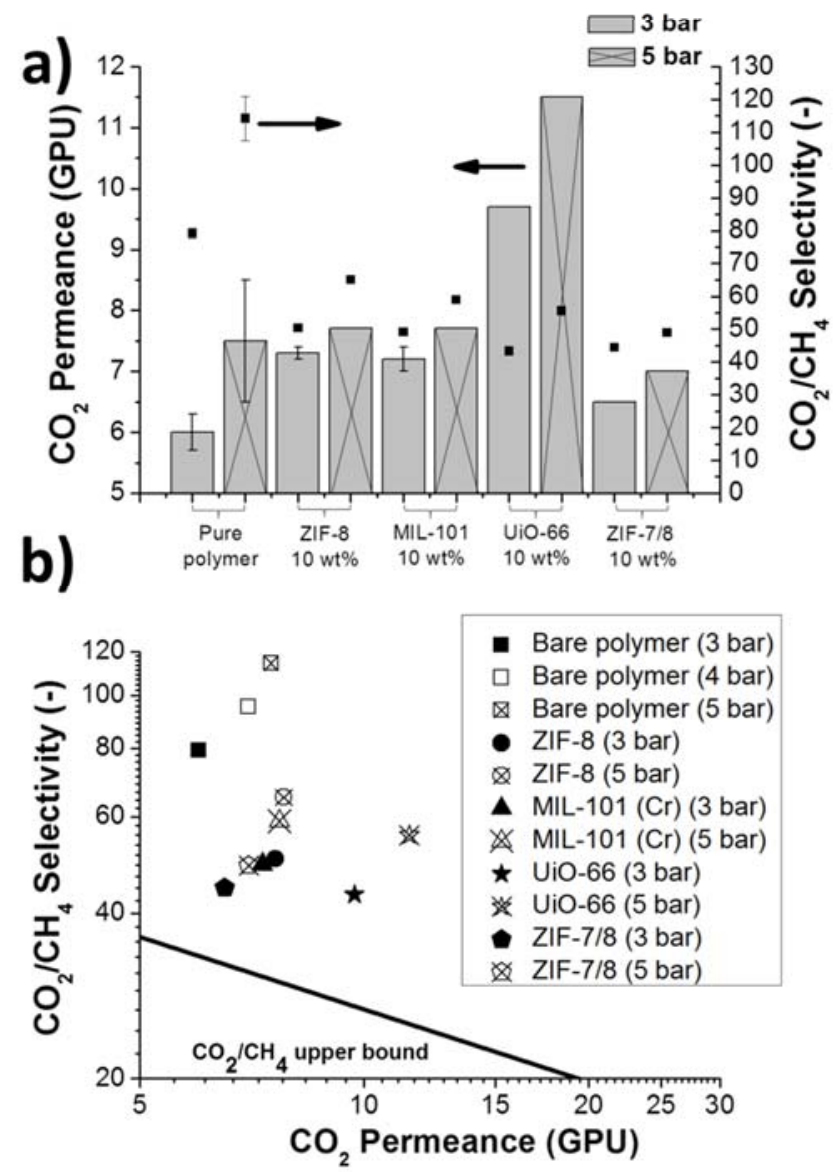

Fig. 5. Comparison among the gas separation performance of pristine Pebax 1657 and the different supported on P84 $4^{\circ}$ MMMs in form of histogram (a) and upper bound type graph (b). 
the different MMMs, making them still very attractive. The best value was obtained for the ZIF- 8 MMMs, with a $\mathrm{CO}_{2} / \mathrm{CH}_{4}$ selectivity of 65.1 (with 7.7 GPU of $\mathrm{CO}_{2}$ ) at 5 bar. This result is logic since ZIF-8, besides having a moderate $\mathrm{CO}_{2}$ adsorption, is the MOF with the narrowest pore access $(0.34 \mathrm{~nm})$, between the kinetic diameters of $\mathrm{CO}_{2}$ and $\mathrm{CH}_{4}(0.33$ and $0.36 \mathrm{~nm}$, respectively). The narrowest porosity of $\mathrm{ZIF}-7 / 8$ material (see Table 1), which is the worst performer interns of $\mathrm{CO}_{2} / \mathrm{CH}_{4}$ selectivity, may hinder the transport of $\mathrm{CO}_{2}$ in comparison with the other MOFs.

Considering separately the effect of diffusivity and selectivity of the MOFs in the gas separation performance of the membranes, ZIF- 8 and ZIF-7/8 core-shells are expected to have more effect on the diffusivity term thanks to their narrower pore distribution (see Table 1). On the contrary, UiO-66 and MIL-101(Cr) may have a greater effect on the contribution of the solubility due to their higher $\mathrm{CO}_{2}$ uptake (see Table 1 ).

The gas separation performance of all MMMs were plotted on a selectivity-permeance graph (Fig. 5b). Since the Robeson upper bound was originally defined in Barrer $\left({ }^{48}\right.$, see the values of Table S3 from the ESI+), a new upper bound was calculated in GPU to obtain a more accurate comparison (Fig. S7 from the ESI+). The Robeson upper bound, revisited in $2008^{48}$ was defined from pure component permeability data of dense membranes, allowing the determination of the state-of-the-art limits for gas separation with polymeric membranes. The upper bound relationship is expressed by $P_{i}=k \cdot \alpha_{i j}^{n}$, where $P_{i}$ is the permeability of the more permeable gas, $\alpha$ is the separation factor $\left(P_{i} / P_{j}\right)$ and $n$ is the slope of the log-log limit. It was observed that the representation of $-1 / n$ vs. $d_{i j}$ (where $d_{i j}$ is the difference between the gas molecular diameters $\left(d_{j}-d_{i}\right)$ ) yielded a straight line relationship. Since the gas permeability was defined for the explained purpose in Barrer, a new $\mathrm{CO}_{2} / \mathrm{CH}_{4}$ upper bound relationship in GPU has been calculated here. This used the values from the literature that defined the original upper bound but changing permeabilities in Barrer by permeances in GPU (see Table S3 from the ESI + ), as done in a previous work for $\mathrm{H}_{2} / \mathrm{CO}_{2}$ mixtures. ${ }^{37}$ The thicknesses used have been those reported in the publications cited in Table S3 from the ESIt, although possible inaccuracies in the ex situ measurement of this length, such as experimental errors or membrane swelling, might affect such values. These values were represented in Fig. S7 from the ESIt and fitted to a logarithmic equation, resulting in the following upper bound relationship: $P_{\mathrm{CO}_{2}}=8175 \cdot \alpha_{\mathrm{CO}_{2} / \mathrm{CH}_{4}}^{-2.086}$. A factor $k$ of $8175 \mathrm{GPU}$ was obtained and the slope $n$ of -2.086 was not far from the value found in the original publication (-2.636). Fig. 5b shows that all the membranes prepared in this work clearly surpassed the new calculated upper bound, reaching the so-called commercially attractive region. UiO-66 MMMs performed the highest $\mathrm{CO}_{2}$ permeances, followed by MIL-101(Cr) MMMs, thanks to their wide porosity (see Table 1). On the contrary, ZIF$7 / 8 \mathrm{MMMs}$ are the least permeable and they also contain the fillers with the narrowest pore distribution. ZIF-8 MMMs are the best balanced membranes, showing a great $\mathrm{CO}_{2} / \mathrm{CH}_{4}$ selectivity with high $\mathrm{CO}_{2}$ permeance.

\section{CONCLUSIONS}

Thin membranes of Pebax 1657 have been successfully prepared on dense PTMSP and asymmetric porous P84 supports. The obtained supported Pebax 1657 membranes, with a thickness ranging from 2-3 $\mu \mathrm{m}$, have been characterized showing a good compatibility and adhesion between the support and selective layer. The membranes were tested for the $\mathrm{CO}_{2} / \mathrm{CH}_{4}$ separation at $35{ }^{\circ} \mathrm{C}$ and different feed pressures (3-5 bar), noticing an improvement in both the $\mathrm{CO}_{2}$ permeance and the $\mathrm{CO}_{2} / \mathrm{CH}_{4}$ selectivity with increasing pressures thanks to the favored $\mathrm{CO}_{2}$ solubility. While the Pebax $1657 /$ PTMSP membranes performed similarly to those of self-supported dense Pebax ${ }^{\oplus}$, the Pebax ${ }^{\circledR} 1657 / \mathrm{P}^{\circ} 4^{\circ}$ composites showed a great enhancement in the $\mathrm{CO}_{2} / \mathrm{CH}_{4}$ selectivity thanks to the synergistic compatibility between the two polymers. Thin MMMs of Pebax 1657 containing 10 wt\% of ZIF-8, MIL-101(Cr), UiO-66 and ZIF-7/8 core-shell nanoparticles were also prepared supported on $\mathrm{P}^{\circ} 4^{\circ}$. The incorporation of MOFs enhanced the $\mathrm{CO}_{2}$ permeance of the membranes in $6 \%$ average, but especially embedding UiO-66, which allowed doubling the permeance of pristine Pebax 1657 membranes. ZIF-8 MMMs are the best performing composites, keeping a high $\mathrm{CO}_{2}$ permeance with a good $\mathrm{CO}_{2} / \mathrm{CH}_{4}$ selectivity. In any event, it has been demonstrated that the good physicochemical interaction between polymer Pebax ${ }^{\circ} 1657$ and $\mathrm{P}^{\circ} 4^{\circ}$ support allowed an enhancement in the $\mathrm{CO}_{2} / \mathrm{CH}_{4}$ separation. The highest $\mathrm{CO}_{2} / \mathrm{CH}_{4}$ selectivity obtained along the work was that of the membrane made of bare Pebax 1657 on P84 ${ }^{\circ}$, with a value of 114 (at 7.5 GPU of $\mathrm{CO}_{2}$ ).

\section{Conflicts of interest}

There are no conflicts to declare.

\section{Acknowledgements}

Financial support from the Spanish MINECO and FEDER (MAT2016-77290-R), the Aragón Government (T43-17R) and 


\section{NJC}

the ESF is gratefully acknowledged. J. S.-L. thanks the Spanish Education Ministry Program FPU2014 for his PhD grant. All the microscopy work was done in the Laboratorio de Microscopías Avanzadas at the Instituto de Nanociencia de Aragón (LMAINA). Finally, the authors would like to acknowledge the use of the Servicio General de Apoyo a la Investigación-SAI, Universidad de Zaragoza.

\section{BIBLIOGRAPHY}

1 M. Poloncarzova, J. Vejrazka, V. Vesely and P. Izak, Angew. Chem. Int. Ed., 2011, 50, 669-671.

2 Y. Zhang, J. Sunarso, S. Liu and R. Wang, Int. J. Greenhouse Gas Control, 2013, 12, 84-107.

3 S. Rasi, A. Veijanen and J. Rintala, Energy, 2007, 32, 13751380.

4 J. C. Chen, X. Feng and A. Penlidis, Sep. Sci. Technol., 2005, 39, 149-164.

5 A. Baccioli, M. Antonelli, S. Frigo, U. Desideri and G. Pasini, Appl. Energy, 2018, 217, 328-335.

6 L. Deng and M. Hägg, Int. J. Greenhouse Gas Control, 2010, 4, 638-646.

7 M. Pérez-Fortes, J. C. Schöneberger, A. Boulamanti and E. Tzimas, Appl. Energy, 2016, 161, 718-732.

8 B. Li, Y. Duan, D. Luebke and B. Morreale, Appl. Energy, 2013, 102, 1439-1447.

9 V. Bondar, B. Freeman and I. Pinnau, J. Polym. Sci., Part B: Polym. Phys., 2000, 38, 2051-2062.

10 J. H. Kim, S. Y. Ha and Y. M. Lee, J. Membr. Sci., 2001, 190, 179-193.

11 G. Valenti, A. Arcidiacono and J. A. N. Ruiz, Biomass Bioenergy, 2016, 85, 35-47.

12 Z. Dai, L. Ansaloni and L. Deng, Green Energy Environ., 2016, 1, 102-128.

13 P. D. Sutrisna, J. Hou, M. Y. Zulkifli, H. Li, Y. Zhang, W. Liang, D. D'Alessandro and V. Chen, J. Mater. Chem. A, 2018, 6, 918-931.

14 Y. Wang, T. Hu, H. Li, G. Dong, W. Wong and V. Chen, Energy Procedia, 2014, 63, 202-209.

15 E. Esposito, G. Clarizia, P. Bernardo, J. C. Jansen, Z. Sedláková, P. Izák, S. Curcio, B. d. Cindio and F. Tasselli, Chem. Eng. Process. Process Intensif., 2015, 94, 53-61.

16 A. Car, C. Stropnik, W. Yave and K. Peinemann, Sep. Purif. Technol., 2008, 62, 110-117.

17 P. Li, Z. Wang, W. Li, Y. Liu, J. Wang and S. Wang, ACS Appl. Mater. Interfaces, 2015, 7, 15481-15493.

18 L. Liu, A. Chakma and X. Feng, Chem. Eng. J., 2004, 105, 4351.
19 G. Dong, H. Li and V. Chen, J. Mater. Chem. A, 2013, 1, 46104630.

20 L. Xu, L. Xiang, C. Wang, J. Yu, L. Zhang and Y. Pan, Chin. J. Chem. Eng., 2017, 25, 882-891.

21 W. Zheng, R. Ding, K. Yang, Y. Dai, X. Yan and G. He, Sep. Purif. Technol., 2018, DOI: 10.1016/j.seppur.2018.04.010..

22 T. Li, Y. Pan, K. Peinemann and Z. Lai, J. Membr. Sci., 2013, 425, 235-242.

23 A. Sabetghadam, X. Liu, M. Benzaqui, E. Gkaniatsou, A. Orsi, M. M. Lozinska, C. Sicard, T. Johnson, N. Steunou, P. A. Wright, C. Serre, J. Gascon, F. Kapteijn, Chem.-A Eur. J., 2018, 24, 7949-7956.

24 S. Meshkat, S. Kaliaguine and D. Rodrigue, Sep. Purif. Technol., 2018, 200, 177-190.

25 M. Isanejad, N. Azizi and T. Mohammadi, J Appl Polym Sci, 2017, 134, 44531-44540.

26 J. Sánchez-Laínez, A. Veiga, B. Zornoza, S. R. Balestra, S. Hamad, A. R. Ruiz-Salvador, S. Calero, C. Téllez and J. Coronas, J. Mater. Chem. A, 2017, 5, 25601-25608.

27 S. K. Nune, P. K. Thallapally, A. Dohnalkova, C. Wang, J. Liu and G. J. Exarhos, Chem. Commun., 2010, 46, 4878-4880.

28 J. H. Cavka, S. Jakobsen, U. Olsbye, N. Guillou, C. Lamberti, S. Bordiga and K. P. Lillerud, J. Am. Chem. Soc., 2008, 130, 13850-13851.

29 D. Sun, Y. Fu, W. Liu, L. Ye, D. Wang, L. Yang, X. Fu and Z. Li, Chem.-A Eur. J., 2013, 19, 14279-14285.

$30 \mathrm{H}$. Wu, Y. S. Chua, V. Krungleviciute, M. Tyagi, P. Chen, T. Yildirim and W. Zhou, J. Am. Chem. Soc., 2013, 135, 1052510532.

31 J. Benito, S. Sorribas, I. Lucas, J. Coronas and I. Gascon, ACS Appl. Mater. Interfaces, 2016, 8, 16486-16492.

32 G. Ferey, C. Mellot-Draznieks, C. Serre, F. Millange, J. Dutour, S. Surble and I. Margiolaki, Science, 2005, 309, 2040-2042.

33 P. L. Llewellyn, S. Bourrelly, C. Serre, A. Vimont, M. Daturi, L. Hamon, G. De Weireld, J. Chang, D. Hong, Y. Kyu Hwang, S.H. Jhung and G. Férey, Langmuir, 2008, 24, 7245-7250.

34 N. Liédana, A. Galve, C. Rubio, C. Téllez and J. Coronas, ACS Appl. Mater. Interfaces, 2012, 4, 5016-5021.

35 L. Hou, L. Wang, N. Zhang, Z. Xie and D. Dong, Polym. Chem., 2016, 7, 5828-5834.

36 N. A. Khan, I. J. Kang, H. Y. Seok and S. H. Jhung, Chem. Eng. J., 2011, 166, 1152-1157.

37 J. Sánchez-Laínez, B. Zornoza, C. Téllez and J. Coronas, J. Membr. Sci., 2018, 563, 427-434.

38 F. H. Akhtar, M. Kumar and K. Peinemann, J. Membr. Sci., 2017, 525, 187-194. 


\section{NJC}

\section{PAPER}

39 J. J. Ge, G. Xue, F. Li, K. W. McCreight, S. Wang, F. W. Harris, S. Z. Cheng, X. Zhuang, S. Hong and Y. Shen, Macromol. Rapid Commun., 1998, 19, 619-623.

40 J. H. Kim and Y. M. Lee, J. Membr. Sci., 2001, 193, 209-225.

41 A. Ghadimi, M. Amirilargani, T. Mohammadi, N. Kasiri and B. Sadatnia, J. Membr. Sci., 2014, 458, 14-26.

42 S. Sridhar, R. Suryamurali, B. Smitha and T. Aminabhavi, Colloids Surf. Physicochem. Eng. Aspects, 2007, 297, 267274.

43 K. Berean, J. Z. Ou, M. Nour, K. Latham, C. McSweeney, D. Paull, A. Halim, S. Kentish, C. M. Doherty, A. J. Hill and K. Kalantar-Zadeh, Sep. Purif. Technol., 2014, 122, 96-104.

44 S. Sridhar, R. Veerapur, M. Patil, K. Gudasi and T. Aminabhavi, J. Appl. Polym. Sci., 2007, 106, 1585-1594.

45 M. Askari, M. L. Chua and T. S. Chung, Ind. Eng. Chem. Res., 2014, 53, 2449-2460.

46 J. Schultz and K. Peinemann, J. Membr. Sci., 1996, 110, $37-$ 45.

47 S. Stern, J. Mullhaupt and P. Gareis, AIChE J., 1969, 15, 6473.

48 L. M. Robeson, J. Membr. Sci., 2008, 320, 390-400. 